\title{
IN-SITU TENSILE AND CORROSION DAMAGE CHARACTERIZATION OF FIBER-REINFORCED CEMENTITIOUS COMPOSITES USING X-RAY MICRO-COMPUTED TOMOGRAPHY
}

\author{
WILSON NGUYEN ${ }^{\dagger, *}$, DANIEL HERNÁNDEZ-CRUZ ${ }^{\dagger \dagger}$, KEMAL CELIK $^{\dagger}$, \\ JACOB F. DUNCAN ${ }^{\dagger}$, PAULO J.M. MONTEIRO ${ }^{\dagger}$ AND CLAUDIA P. OSTERTAG ${ }^{\dagger}$ \\ ${ }^{\dagger}$ University of California, Berkeley \\ Berkeley, CA USA \\ e-mail: willnguyen@berkeley.edu (W. Nguyen) \\ e-mail:kcelik@berkeley.edu (K. Celik) \\ e-mail: jduncan@berkeley.edu (J.F. Duncan) \\ e-mail: monteiro@ce.berkeley.edu (P.J.M. Monteiro) \\ e-mail: ostertag@ce.berkeley.edu (C.P. Ostertag) \\ ${ }^{\dagger}$ Universidad Autonóma de Chiapas \\ Tuxtla Gutiérrez, Chiapas, Mexico \\ e-mail: daniel.hernandez@unach.mx (D. Hernández-Cruz)
}

Key words: Fiber, Strain-hardening cementitious composite, Tomography, Direct tension, Corrosion, Crack

\begin{abstract}
Use of fibers in high-performance fiber-reinforced cementitious composites has been shown to have a significant influence on the overall toughening of the composite material compared to conventional concrete. However, nondestructive analysis of microscale damage may be difficult to obtain, including cracking caused by long-term internal expansive processes such as corrosion product formation. In this study, synchrotron-based hard X-ray micro-computed tomography $(\mu \mathrm{CT})$ is utilized as a nondestructive method to obtain internal spatial information of cracked strainhardening cementitious composites (SHCC). Imaging of specimens was performed under two insitu loading conditions - the first being under direct tension and the second being periodic scanning under long-term corrosion damage of reinforced SHCC. For the latter series of experiments, specimens were subjected to various intensities of cracking prior to corrosion to investigate the effect of cracking on corrosion behavior. Tomographic results revealed that progressive microcrack initiation and propagation behavior could be successfully observed during direct tensile loading. Crack morphology of the cover cementitious matrix had a significant influence on the corrosion damage and SHCC showed a higher matrix cracking resistance compared to non-fiber-reinforced cementitious composites.
\end{abstract}

\section{INTRODUCTION}

Fibers in a properly designed cement-based composite increase the resistance to crack propagation, promote the initiation of diffusive cracking throughout the cementitious matrix and lead to significant toughness enhancement compared to conventional concrete. In particular, use of polyvinyl alcohol (PVA) microfibers (approximately $40 \mu \mathrm{m}$ diameter) has been found to be effective for a number of composite designs, either as primary fiber reinforcement or as part of a hybrid design [1, 
2].

The observable cracking behavior of fiberreinforced composites under load is often restricted to features at the surface. While information on the internal cracking network of a sample may be obtained after destructive testing, cutting can introduce additional cracking that may not be discernable from preexisting cracks. Damage caused by internal durability-related stresses, such as steel corrosion within reinforced concrete, is notably difficult to characterize due to the uncertainty of the sites of damage within the composite volume and the long-term exposure required to induce such damage. Destructive testing may be used to evaluate accumulated damage, though provides limited information on the rate of damage.

The research reported herein investigates the use of synchrotron-based hard X-ray micro-computed tomography $(\mu \mathrm{CT})$, a nondestructive, high-resolution spatial imagining technique, for in-situ damage characterization of PVA microfiber-reinforced cementitious composites under two primary causes of concrete damage - applied tensile stress and long-term, natural steel corrosion. Researchers have used this technique to study the in-situ crack development of loaded cementitious composites without fiber reinforcement $[3,4]$ and internal, expansive product formation caused by durability phenomena in cementitious materials [5-7]. The present preliminary findings show that $\mu \mathrm{CT}$ is an appropriate tool for visualizing progressive cracking damage in fiber-reinforced cementitious composites under direct tension and under internal corrosion damage. Greater emphasis is given to the description of the damage caused by the long-term corrosion.

\section{MATERIALS AND SPECIMENS}

\subsection{SHCC}

The mixture proportions for the strainhardening cementitious composite (SHCC) and plain cementitious composite (PCC) are presented in Table 1. The initial composite design was based on the hybrid fiber- reinforced concrete (HyFRC) design developed by Blunt and Ostertag [2], which utilizes $0.2 \%$ volume fraction of PVA microfibers, with a total fiber volume fraction of $1.5 \%$ when accounting for steel fibers. Preliminary testing of mortars with a PVA fiber volume content of up to $1.5 \%$, based on composite volume, did not exhibit satisfactory distributive cracking behavior. A fiber volume fraction of $3.5 \%$ was found to be acceptable in producing the desired multiple cracking in tested samples. When normalizing the fiber volume fraction by the cementitious paste volume, rather than total composite volume, the designed value for SHCC (4.14\%) was nearly equivalent to that of HyFRC $(4.07 \%)$. Fibers for SHCC had a diameter of $38 \mu \mathrm{m}$ and a length of $8 \mathrm{~mm}$, matching the same type used for HyFRC. A typical tensile response of the SHCC using an apparatus designed for simultaneous loading and tomographic imaging (to be discussed in Section 3.1) is shown in Figure 1. The displacement includes slip from the loading apparatus.

Table 1: SHCC and PCC mixture proportions (per $\mathrm{m}^{3}$ ).

\begin{tabular}{lcc}
\hline & SHCC & PCC \\
\hline Cement type II/V (kg) & 560 & 580 \\
\hline Fly ash class F (kg) & 670 & 690 \\
\hline Fine aggregate (kg) & 320 & 330 \\
\hline Water (kg) & 330 & 350 \\
\hline $\begin{array}{l}\text { Superplasticizer } \\
\text { (wt. \% binder) }\end{array}$ & 0.69 & 0.69 \\
\hline $\begin{array}{l}\text { Viscosity modifying admix. } \\
\text { (wt. \% binder) }\end{array}$ & 0.33 & 0.33 \\
\hline PVA fibers (vol. \% SHCC) & 3.5 & - \\
\hline
\end{tabular}

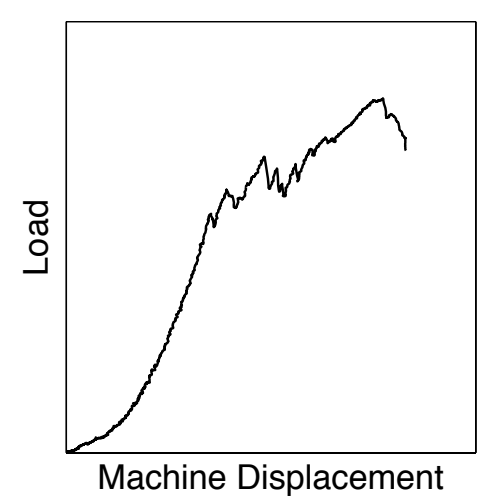

Figure 1: Typical SHCC tensile response, including initial mechanical slip. 
To accommodate for the high fiber content while maintaining suitable workability for casting, $55 \%$ of cement mass was substituted by fly ash class F. A water-to-binder ratio of 0.28 was found to be suitable for minimizing the severity of bleeding.

\subsection{Design of the specimen configuration}

The experiments required specimens that could be tested under direct tension while inducing cracks within a known region of interest. Two designs were used. The first design, considering the load scenario of direct tension only, is detailed in Figure 2a. The external curvature concentrated the cracking near the specimen's midheight, where imaging would take place, and the circular cross section maintained a uniform thickness upon rotation about the specimen's longitudinal axis, which is favorable for $\mu \mathrm{CT}$ measurements.

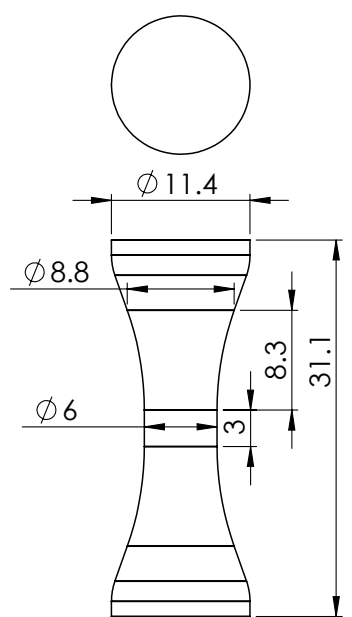

(a)

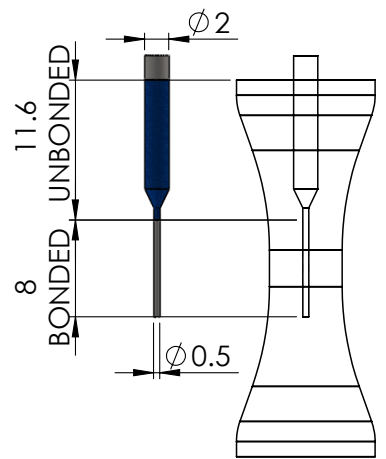

(b)
Figure 2: Specimen details (mm): (a) Direct tensile testing only; (b) Direct tensile and corrosion testing.

The second type of sample (Figure 2b), aimed to study corrosion damage, had the same external dimensions as the direct tension samples, except that a steel rod was embedded along the specimen's longitudinal axis and allowed to extrude from the cementitious composite surface (Figure 2b). The specimens were preloaded to induce microcracks prior to corrosion activity to simulate the cracks existing in the concrete cover. Cracks can have great influence on the corrosion resistance of reinforced concrete elements [8]. It has been reported that fiber-reinforced concrete is less susceptible to corrosion damage due to limitation of crack width during loading [911]. The present experiments aim to provide microstructural information on how the crack size and distribution influence the corrosion process.

A steel rod was lathed from a No. 3 (9.5 $\mathrm{mm}$ diameter) A615 steel reinforcing bar, commonly used in reinforced concrete construction in the United States, and thinned down to a diameter of at most $0.5 \mathrm{~mm}$ within the region of interest for imaging. This region was defined along an 8-mm length of the rod that was bonded directly to the cementitious matrix. Elsewhere, the rod was coated with an electrically-insulating lacquer and polytetrafluoroethylene (PTFE) tape to prevent corrosion of the bar. An insulated copper wire was soldered to the extruded portion of the steel rod to allow for electrochemical testing, with the solder joint protected by electrical and PTFE tape (Figure 3).

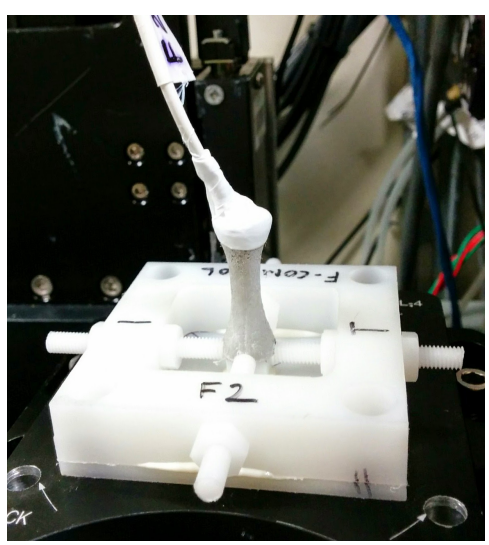

Figure 3: Specimen for corrosion testing.

All specimens were cast using 3D-printed molds to ensure accurate dimensions. After casting, the specimens were cured within their formwork in a moist room for two days, demolded, and then placed in a limewater bath. Imaging of the SHCC sample under direct tension occurred at a specimen age of 5 days, while the preloading of the corrosionrelated samples took place after 12 total days of curing. 


\section{EXPERIMENTAL METHODS}

\subsection{Loading protocol}

Uniaxial tensile loading of the SHCC specimen was performed with an existing testing apparatus that accommodated in-situ tomographic imaging of loaded samples. Figure 4 shows the apparatus and specimen setup. The specimen was subjected to tensile loading by encasing the extremities of the sample within stainless steel loading heads. Brass spheres attached to the loading heads allowed for the specimen to be compatible with the testing apparatus' ball and socket connection. This testing setup resulted in some slip between components once load was applied, as it could be observed in the initial non-linear response of the load-displacement diagram (see Figure 1). Load was applied by a stepper motor while displacement was measured by a linear variable differential transformer (LVDT) that was positioned between an elevating loading stage displaced by the motor and a fixed stage of the testing apparatus. Due to the limited time on the synchrotron beamline, one SHCC sample was considered for imaging under direct tensile conditions. The specimen was subjected to a displacement-controlled rate of $1.3 \mu \mathrm{m}$ per second.

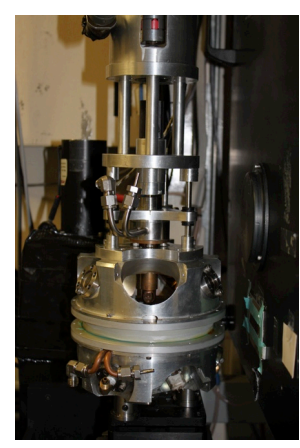

(a)

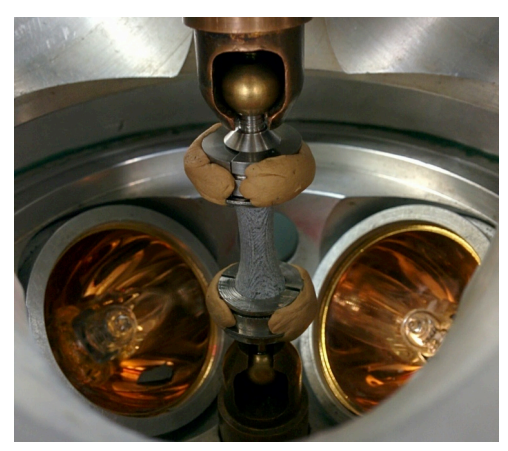

(b)
Figure 4: Tensile testing setup: (a) Global view; (b) Interior view, showing specimen with ball and socket connection.

The preloaded specimens for the corrosion experiment were mechanically tested using the same setup. The severity of induced damage was dependent on the type of cementitious composite. The reinforced PCC sample was loaded until the formation of a dominant crack, which caused a significant decrease in load resistance, and then completely unloaded. The SHCC sample was loaded until the matrix cracking load was reached, which was detectable by a discrete decrease in the load resistance, and then allowed to be displaced an additional $100 \mu \mathrm{m}$ to allow for multiple cracking prior to unloading. It should be noted that imaging of these specimens occurred only after the conclusion of applied load, and did not include sequential scanning during mechanical testing.

\subsection{Corrosion testing}

While a number of researchers have investigated the corrosion of embedded steel within cementitious composites using X-ray micro-computed tomography or X-ray computed tomography $[7,12,13]$, the method for inducing corrosion depended upon the accelerated corrosion method. Often an impressed current is applied on the steel, but this process may lead to different results compared to long-term corrosion under normal conditions $[14,15]$. To avoid this limitation, corrosion of the embedded steel was caused by exposure of the samples to periodic cycles of wetting and drying over an experimental duration of at least 44 weeks. A cycle typically consisted of three days of immersion in 3.5\% sodium chloride solution (by mass) and four days of drying in ambient laboratory conditions.

\subsection{X-ray micro-computed tomography}

The hard X-ray micro-computed tomography experiments were performed at the Advanced Light Source synchrotron on beamline 8.3.2. The X-ray beam is allowed to penetrate an area of interest and the transmitted intensity is measured by a charge couple device area detector, generating radiographs. The different phases within the heterogeneous cementitious composite, such as cracks, PVA fibers and cement paste, have different X-ray attenuations, allowing for phase differentiation. During a scan, the sample is rotated about an axis perpendicular 
to the horizontal plane over $180^{\circ}$, with 1025 radiographs obtained over this rotation. After image processing, a stack of cross-sectional images is obtained for analysis.

With the synchrotron ring current set at 500 $\mathrm{mA}$, an energy level of $35 \mathrm{keV}$ was used for direct tensile testing of SHCC. For scanning reinforced SHCC and reinforced PCC samples, the energy was increased to $43 \mathrm{keV}$ to account for the high attenuation of the steel embedded within the samples, allowing for appropriate beam transmission. Both experiments utilized the PCO.edge camera with a magnification factor of 2, which yielded a pixel resolution of $3.2 \mu \mathrm{m}$ and allowed for an $8.3 \mathrm{~mm}$ horizontal field of view.

\section{RESULTS AND DISCUSSION}

\subsection{Direct tensile experiment}

The in-situ load-displacement response of the specimen tested inside the $\mu \mathrm{CT}$ chamber is shown in Figure 5. The initial nonlinear response was caused by slippage of testing components. Discontinuities in the loaddisplacement response resulted from pausing of the applied displacement to acquire the image, causing small load relaxation. The points shown on the load-displacement curve (Figure 5) indicate when tomograms of the sample were taken. High-contrast crosssectional images of the specimen at increasing intensities of damage are shown in Figure 7.

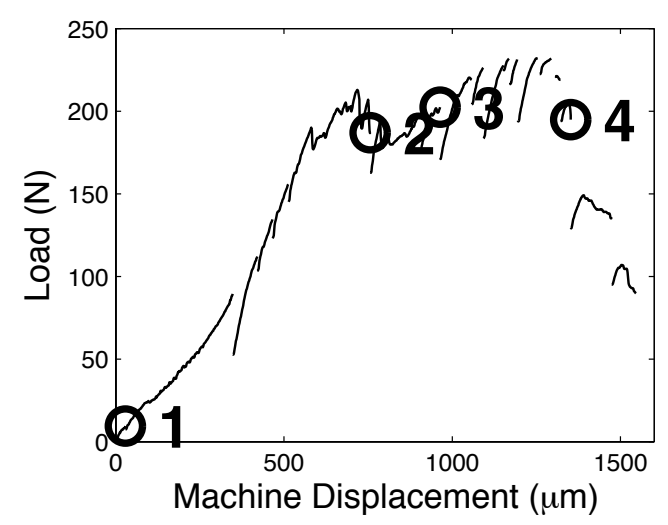

Figure 5: Tensile response of SHCC specimen during imaging. Reference points refer to points in Figure 7.
Progressive microcracking within the specimen can be observed as the load increases. Microcracks tended to cluster within the upper half of the specimen (Figure 7b) prior to initiating in the lower half (Figure 7c). Fiber bridging within cracks in the upper portion of the sample allowed for increasing load transfer across crack faces, allowing new microcrack initiation to occur elsewhere in the matrix. Imaging of the specimen within the softening regime of the load-displacement response revealed dominant crack behavior where large crack widths occurred (Figure 7d). Additional work is currently underway to quantify the cracking mechanisms of the sample using the obtained tomograms, focusing on the spatial distribution of the fibers and cracks.

\subsection{Corrosion experiment}

Corrosion damage observations are presented for two specimens, which are designated by material (SHCC or PCC) and preload severity (peak (P) or intermediate (I)). Load-displacement results from tensile preloading are plotted in Figure 6. Some contribution from the slip generated by the machine displacement is present. The curve of PCC-P suggests a linear elastic response prior to the formation of a dominant tensile crack, which resulted in a considerable decrease in load resistance. The SHCC sample exhibited a more ductile response in comparison, as demonstrated by hardening behavior after the matrix cracking load was reached.

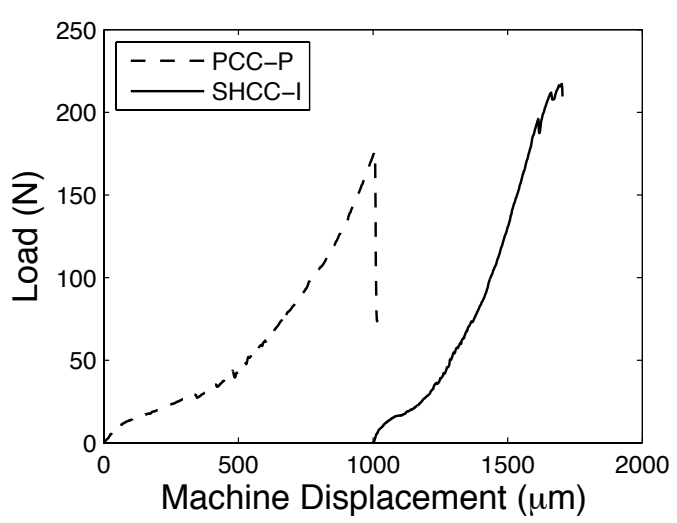

Figure 6: Tensile response of specimens for corrosion testing. 


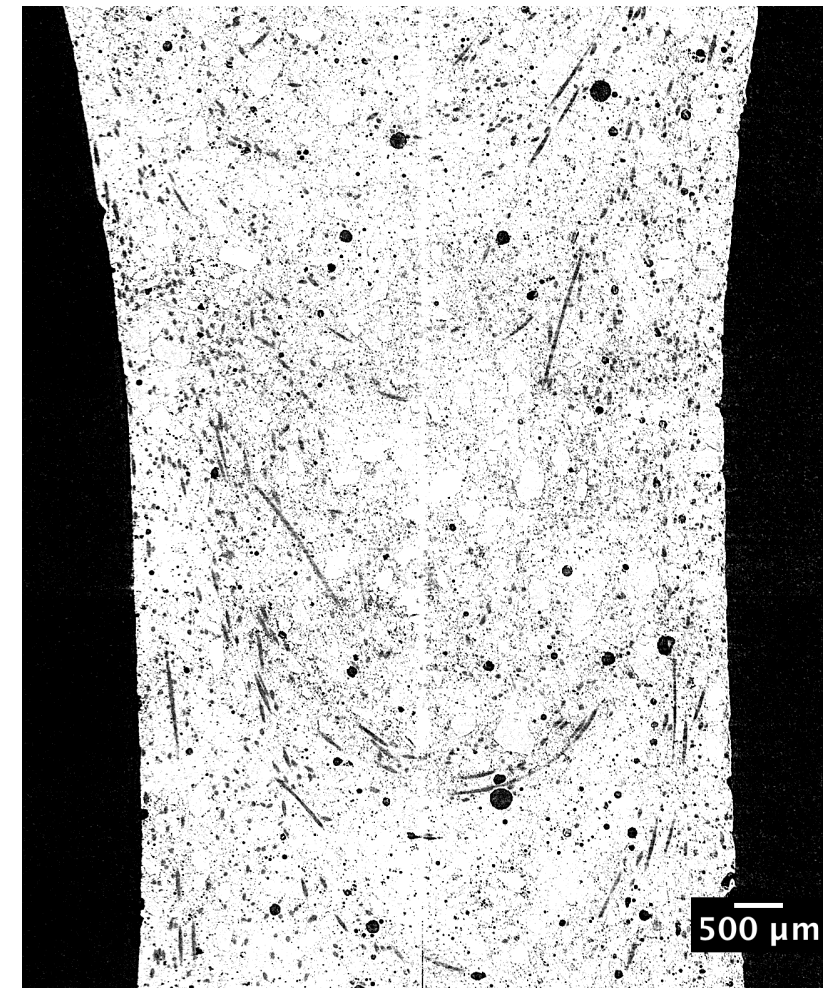

(a) Point 1

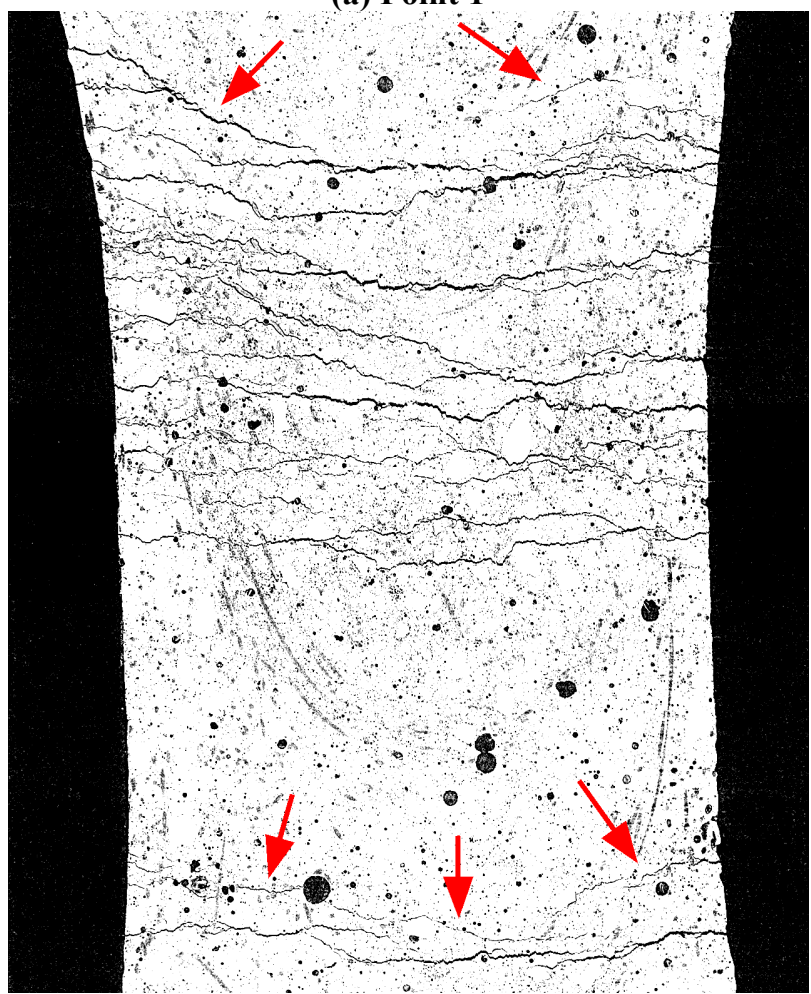

(c) Point 3

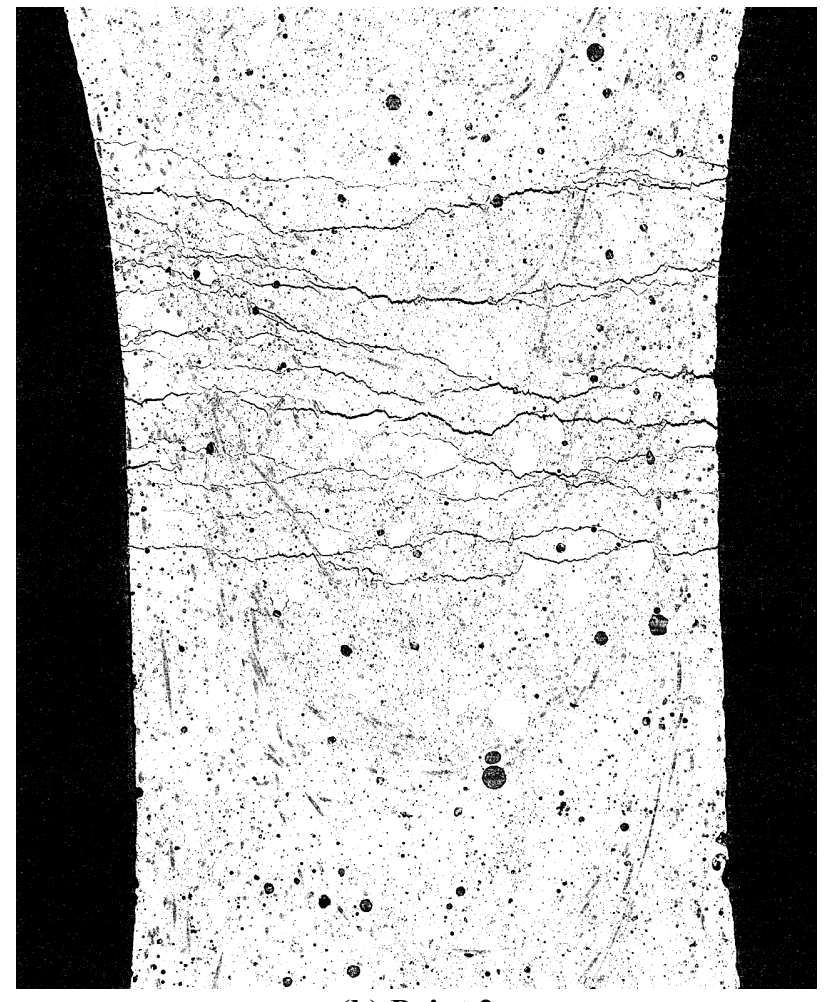

(b) Point 2

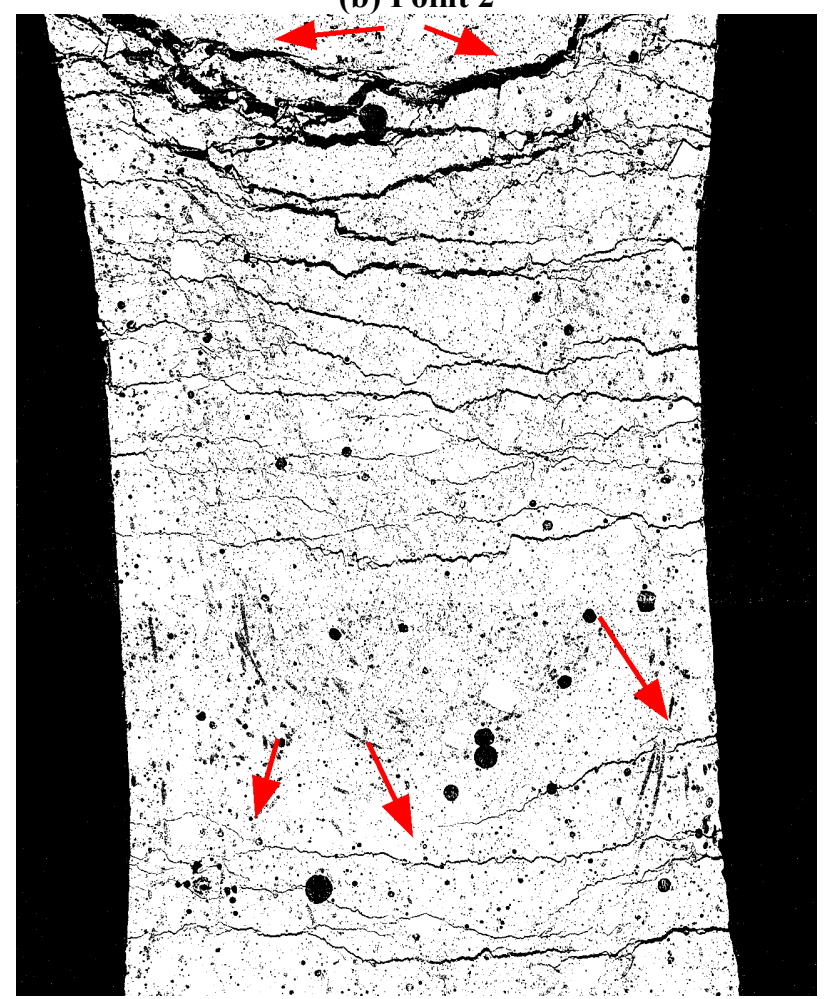

(d) Point 4

Figure 7: Select high-contrast tomograms showing microcrack progression in SHCC sample placed under direct tension. Reference points refer to the points marked in Figure 5. Arrows in (c) and (d) indicate regions of new crack initiation or propagation. 


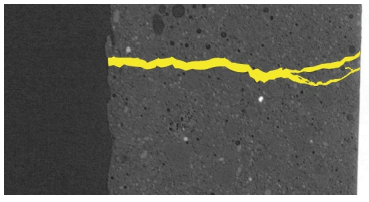

(a) PCC-P, initial precracked state

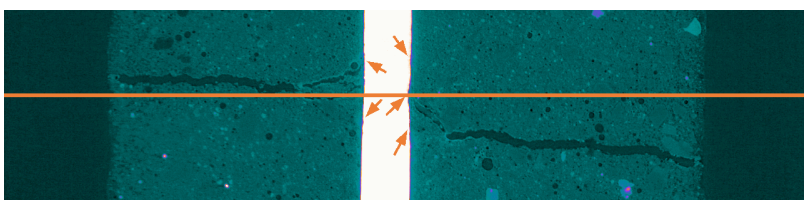

(b) PCC-P, after 5.4 weeks
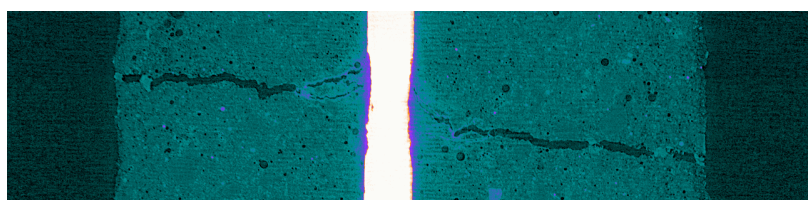

(c) PCC-P, after 9.1 weeks

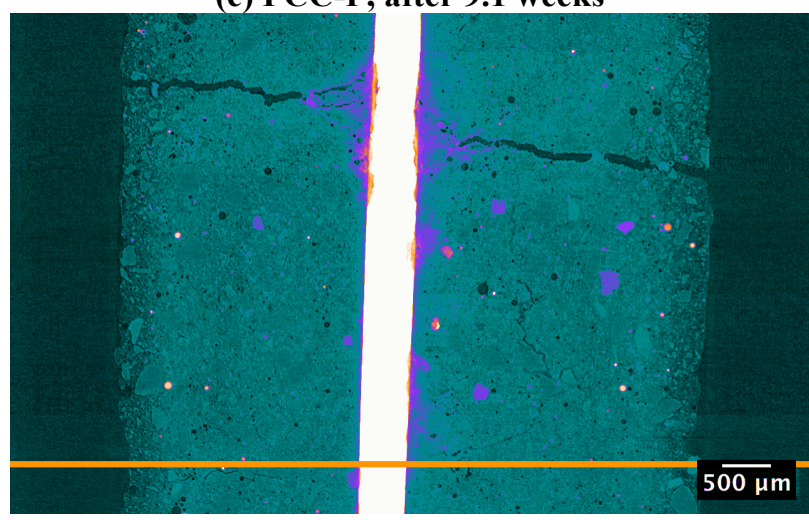

(d) PCC-P, after 43.6 weeks

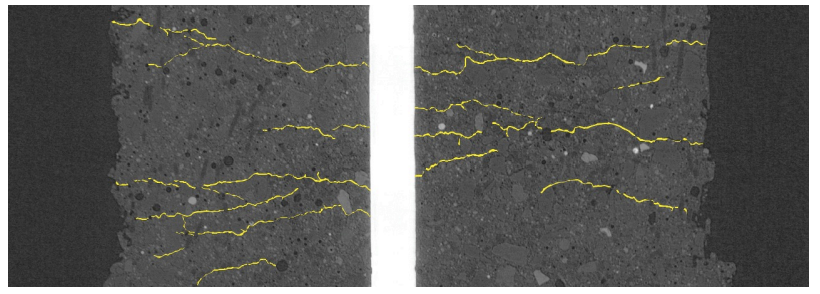

(e) SHCC-I, initial precracked state

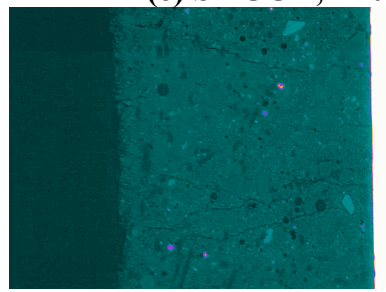

(f) SHCC-I, after 5.4 weeks

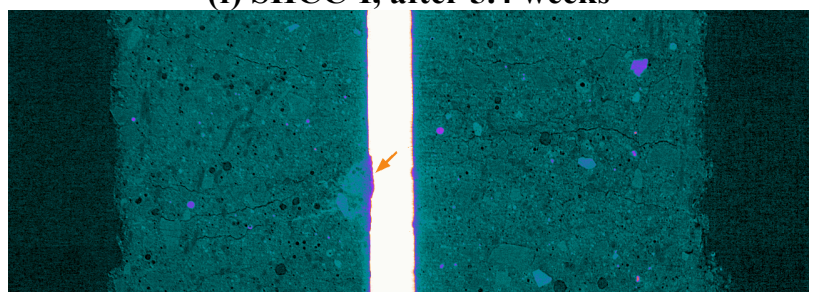

(g) SHCC-I, after 9.1 weeks

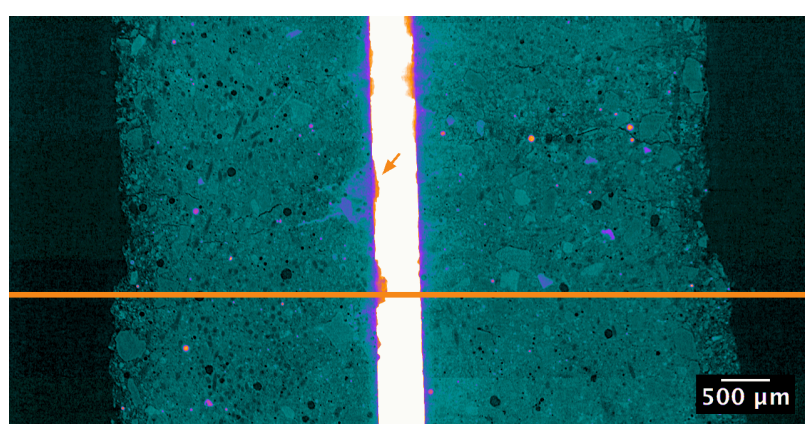

(h) SHCC-I, after 43.6 weeks

Figure 8: Select tomograms showing progressive corrosion damage: (a)-(d) PCC-P; (e)-(h) SHCC-I. Identifiable cracks in the initial state are highlighted in yellow. Tomograms obtained during corrosion experimentation are presented in false-color to enhance phase differentiation. Horizontal line in (b) refers to cross section location shown in Figure 9. Horizontal lines in (d) and (h) refer to cross section location shown in Figure 10. The arrows in (g) and (h) indicate the same location, for reference.

Figure 8 presents select tomograms of the samples' vertical cross sections. Observable cracks in the initial cracked state (prior to induced corrosion) are highlighted in yellow, while subsequent tomograms are converted from grayscale images to false-color images to visually improve phase differentiation. Based on grayscale images, and resulting false-color images, corrosion products appear to show varying degrees of intensity, suggesting nonuniform corrosion product density within the samples. Some high-density aggregates exhibit similar intensity values as corrosion products.

The type of preexisting crack morphology was found to be influential on the corrosion initiation of preloaded samples. The PCC-P specimen formed a single crack with an approximate opening of $95 \mu \mathrm{m}$, with no other microcracks detectable away from this dominant crack (Figure 8a). The earliest observation of steel mass loss occurred after 5.4 weeks of exposure to corrosive environments. Arrows in Figure $8 \mathrm{~b}$ indicate 
regions of corrosion onset, while Figure 9 shows the partial cross section of the specimen where the horizontal line in Figure 8b occurs, highlighting the loss of the rod's circular cross section. Additional imaging after 9.1 weeks revealed more prominent steel mass loss, localized at the steel-crack interface (Figure $8 \mathrm{c})$. Corrosion products tended to migrate outward from the steel rod through the crack opening.

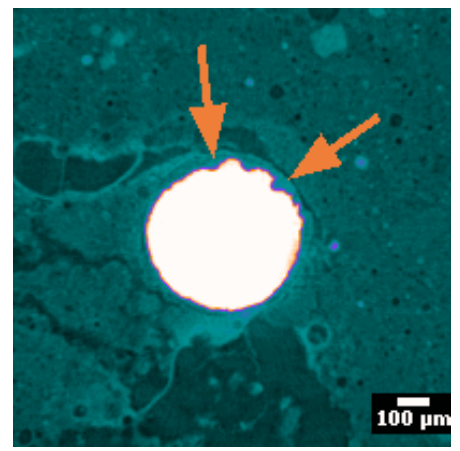

Figure 9: Tomogram in the horizontal plane of PCC-P after 5.4 weeks. Arrows indicate regions of steel mass loss. Tomogram presented in false color.

The SHCC-I specimen exhibited multiple cracking behavior (Figures $8 \mathrm{e}$ ) in contrast to the brittle behavior found in PCC-P. Based on vertical cross-sectional images, the microcrack openings of SHCC-I did not exceed approximately $13 \mu \mathrm{m}$. After 5.4 weeks of sodium chloride solution exposure, no steel mass loss was observable based on reconstructed tomograms (Figure $8 \mathrm{f}$ ), showing delay in corrosion initiation compared to PCC$\mathrm{P}$, which was active at that time. Some corrosion product formation was present after 9.1 weeks, occurring where microcracks intersected the steel rod (Figure 8g), though the bar diameter reduction (17\%) was less than PCC-P (22\%). Even though SHCC-I was subjected to $23 \%$ greater peak load during the preloading portion of the experiment than PCC-P, the performance of SHCC may be considered more desirable due to the corrosion initiation time extension caused by reduction in crack widths formed during loading. The result is consistent with large-scale studies of fiber-reinforced cementitious composites exhibiting a delay in corrosion activity of steel reinforcing bars due to greater crack control of the concrete cover [9-11].

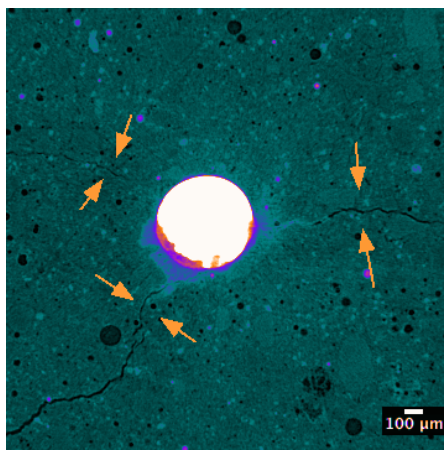

(a) PCC-P, after 43.6 weeks

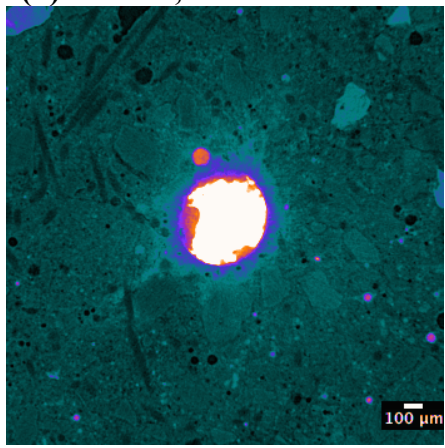

(b) SHCC-I, after 43.6 weeks

Figure 10: Tomograms showing corrosion-induced matrix damage in the horizontal plane: (a) splitting crack formations indicated by arrows; (b) lack of extensive splitting cracks. Tomograms are presented in false color.

With regards to corrosion propagation damage to the cementitious matrix, the use of SHCC provided higher cracking tolerance compared to PCC. Tomograms of the specimens' corrosion propagation behavior is shown in Figure $8 \mathrm{~d}$ and $8 \mathrm{~h}$ for PCC-P and SHCC-I, respectively, after 43.6 weeks of sodium chloride penetration. Figures 10a and $10 \mathrm{~b}$ show partial horizontal cross sections of the tomograms presented in Figures $8 \mathrm{~d}$ and $8 \mathrm{~h}$, respectively. While no splitting (radial) cracks were formed when the steel rod in PCC-P showed initial corrosion product formation (after 5.4 weeks), likely due to the crack void accommodating the volumetric formation of products, corrosion of the steel away from the dominant crack caused such splitting cracks to occur (Figure 10a). In contrast, corrosion activity in SHCC-I did not produce extensive splitting cracks, though minor matrix cracking damage was present near the steel-matrix interface (Figure 10b). Because effective 
crack-resisting mechanisms are not present for PCC, splitting cracks will form when the tensile stresses caused by the growth of corrosion products on the steel surface exceed the capacity of the matrix. This crack morphology has been attributed to poor largescale durability performance of conventional reinforced concrete, due to the unrestricted migration of sodium chloride solution and weakening of reinforcing bar-matrix bonding, compared to fiber-reinforced composites, which often have superior splitting crack resistance [11].

\section{SUMMARY AND CONCLUSIONS}

In this two-part study, X-ray microcomputed tomography $(\mu \mathrm{CT})$ was utilized as a characterization technique for visualizing the in-situ internal damage processes that occur in strain-hardening cementitious composites (SHCC). The following preliminary conclusions can be made:

1. X-ray micro-computed tomography may be used to observe the progressive, internal cracking behavior of fiberreinforced cementitious composites under direct tensile load.

2. Using $\mu \mathrm{CT}$, steel corrosion damage in reinforced SHCC and reinforced plain cementitious composites (PCC) may also be visualized over long-term durations.

3. Compared to PCC, a SHCC matrix containing distributed microcracks resulted in a delay in initial steel mass loss caused by corrosion. Corrosion in the PCC sample initiated locally where the dominant crack intersected the steel rod.

4. After 44 weeks of induced corrosion, SHCC showed negligible matrix cracking damage while PCC exhibited multiple splitting cracks.

\section{ACKNOWLEDGEMENTS}

This work was supported by the Federal Highway Administration (FHWA) through grant DTFH61-09-R-00017. The Advanced Light Source is supported by the Director,
Office of Science, Office of Basic Energy Sciences, of the U.S. Department of Energy under Contract No. DE-AC02-05CH11231.

\section{REFERENCES}

[1] Li, V.C. 2003. On engineered cementitious composites (ECC) a review of the material and its applications. $J A d v$ Concr Technol, 1(3):215-30.

[2] Blunt, J., and Ostertag, C.P. 2009. Performance-based approach for the design of a deflection hardened hybrid fiber-reinforced concrete. $J$ Eng Mech, 135(9):978-86.

[3] Landis, E.N., and Bolander, J.E. 2009. Explicit representation of physical processes in concrete fracture. $J$ Phys $D$ : Appl Phys, 42(21):214002.

[4] Landis, E.N., Nagy, E.N., and Keane, D.T. 2003. Microstructure and fracture in three dimensions. Eng Fract Mech, 70:911-25.

[5] Monteiro, P.J.M., Kirchheim, A.P., Chae, S., Fischer, P., MacDowell, A.A., Schaible, E., and Wenk, H.R. 2009. Characterizing the nano and micro structure of concrete to improve its durability. Cem Concr Compos, 31(8):577-84.

[6] Hernández-Cruz, D., Hargis, C.W., Bae, S., Itty, P.A., Meral, C., Dominowski, J., Radler, M.J., Kilcoyne, D.A., and Monteiro, P.J.M. 2014. Multiscale characterization of chemical-mechanical interactions between polymer fibers and cementitious matrix. Cem Concr Compos, 48:9-18.

[7] Itty, P.-A., Serdar, M., Meral, C., Parkinson, D., MacDowell, A.A., Bjegović, D., and Monteiro, P.J.M. 2014. In situ 3D monitoring of corrosion on carbon steel and ferritic stainless steel embedded in cement paste. Corros Sci, 83:409-18.

[8] Sahmaran, M., and Yaman, I.O. 2008. Influence of transverse crack width on reinforcement corrosion initiation and 
propagation in mortar beams. Can J Civ Eng, 35(3):236-45.

[9] Blunt, J., Jen, G., and Ostertag, C.P. 2015. Enhancing corrosion resistance of reinforced concrete structures with hybrid fiber reinforced concrete. Corros Sci, 92:182-91.

[10] Miyazato, S., and Hiraishi, Y. 2013. Durability against steel corrosion of HPFRCC with bending cracks. $J A d v$ Concr Technol, 11(4):135-43.

[11] Jen, G., and Ostertag, C.P. 2016. Experimental observations of selfconsolidated hybrid fiber reinforced concrete (SC-HyFRC) on corrosion damage reduction. Constr Build Mater, 105:262-8.

[12] Šavija, B., Luković, M., Hosseini, S.A.S., Pacheco, J., and Schlangen, E. 2014. Corrosion induced cover cracking studied by X-ray computed tomography, nanoindentation, and energy dispersive X-ray spectrometry (EDS). Mater Struct.

[13] Erdem, S. 2014. X-ray computed tomography and fractal analysis for the evaluation of segregation resistance, strength response and accelerated corrosion behaviour of self-compacting lightweight concrete. Constr Build Mater, 61:10-7.

[14] Poursaee, A., and Hansson, C.M. 2009. Potential pitfalls in assessing chlorideinduced corrosion of steel in concrete. Cem Concr Res, 39(5):391-400.

[15] El Maaddawy, T.A., and Soudki, K.A. 2003. Effectiveness of impressed current technique to simulate corrosion of steel reinforcement in concrete. $J$ Mat Civ Engin, 15(1):41-7. 